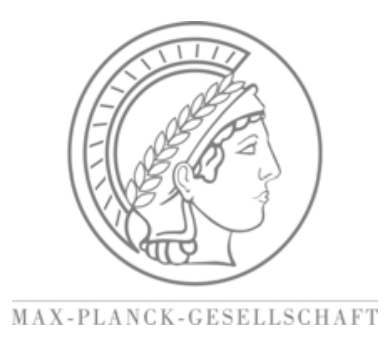

Not invented here: Technology licensing, knowledge transfer and innovation based on public research

Guido Buenstorf Matthias Geissler

The Papers on Economics and Evolution are edited by the Evolutionary Economics Group, MPI Jena. For editorial correspondence, please contact: evopapers@econ.mpg.de

ISSN 1430-4716
Max Planck Institute of Economics Evolutionary Economics Group Kahlaische Str. 10

07745 Jena, Germany Fax: ++49-3641-686868 


\title{
Not invented here: Technology licensing, knowledge transfer and innovation based on public research
}

\author{
Guido Buenstorf* \\ Matthias Geissler \\ Max Planck Institute of Economics \\ Evolutionary Economics Group \\ Kahlaische Strasse 10 \\ 07745 Jena (Germany) \\ buenstorf@econ.mpg.de \\ geissler@econ.mpg.de
}

December 2009

\begin{abstract}
:
Using a new dataset encompassing more than 2,200 inventions made by Max Planck Society researchers from 1980 to 2004, we explore how licensee and technology characteristics affect the licensing and commercialization of technologies from public research. We find no evidence that spin-offs and external licensees systematically differ in their likelihood of successful commercialization. Technologies licensed to foreign firms are less often commercialized, which may reflect selection effects. Patented technologies and inventions by senior scientists are more likely to be licensed, but patent protection is related to lower commercialization odds and lower royalty payments.
\end{abstract}

Keywords: Licensing, public research, cognitive distance, entrepreneurship, Max Planck Society.

JEL classifications: L26, O32, O34.

\footnotetext{
* Corresponding author. We are grateful to Max Planck Innovation GmbH for granting us access to their data. For helpful comments and discussions, we thank Joerg Erselius, Astrid Giegold, Dietmar Harhoff, Bernhard Hertel, Evelyn Kaiser, Lionel Nesta, Vangelis Souitaris and Dieter Treichel. Wolfgang Ziegler and Sebastian Schmidt at the Patent Information Office of the University of Jena helped us assemble the patent database. Wolfhard Kaus provided valuable research assistance. The usual caveat applies.
} 


\section{Introduction}

Throughout the developed economies, public attention and policy measures are increasingly focusing on the transfer of knowledge from public research to the private sector. Following the Bayh-Dole Act in the U.S. and similar legislative changes elsewhere, technology transfer has generally been accepted as a primary objective of universities and other public research organizations (cf. Mowery et al, 2001; Phan and Siegel, 2006; Verspagen, 2006). Notwithstanding the importance of alternative transfer channels (Bozeman, 2000; Cohen et al., 2002; Zellner, 2003), commercialization of scientific results based on patents, licensing, and spin-off entrepreneurship has found particularly intensive scrutiny (Jensen and Thursby, 2001; Shane, 2002; Lowe and Ziedonis, 2006). Yet in spite of the increased emphasis on the protection of universities' intellectual property rights (IPRs) and IPR-based commercialization, we still know little about the underlying processes of knowledge transfer. To learn more about these processes, in the present paper we explore how the success of commercialization activities is related to several licensee and technology characteristics.

Commercializing university inventions is non-trivial because these inventions are often far from being readily marketable. Prior work suggests that the commercialization of results from public research is complicated by uncertainty stemming from the early-stage character of most university inventions (Jensen and Thursby, 2001), information asymmetries between inventor and potential licensee (Shane, 2002), as well as the non-codified nature of important elements of the knowledge base underlying the traded technology (Agrawal, 2006). However, we lack conclusive evidence on how the challenges posed by these traits of university inventions are related to licensee and technology characteristics. For example, the relative commercialization performance of university spin-offs vis-à-vis external licensees is a contested issue (Shane, 2002; Lowe and Ziedonis, 2006). Other issues, including the effectiveness of international licensing, as well as the relationships between different forms of university-industry interaction such as collaborative research and technology licensing, are largely unexplored. Furthermore, most empirical studies are based on U.S. data, and it cannot be taken for granted that their results generalize to other countries and institutional settings.

We begin to address these issues using a newly assembled dataset with detailed information about the licensing activities of the Max Planck Society, Germany's largest nonuniversity public research organization dedicated to basic science. Unlike German universities, the Max Planck Society has consistently been subject to a Bayh-Dole-like IPR 
regime since the 1970s. This enables us to draw on a rich set of inventions and licensing activities, which encompasses more than 2,200 inventions and about 700 license agreements involving royalty payments for the time period 1980-2004. In addition to licensing agreements and inventor information, the data also contain information on royalty payments, indicating whether or not the technology was successfully commercialized in the marketplace as well as the magnitude of the returns from commercialization to the Max Planck Society.

We use this dataset to analyze how licensing and commercialization are affected by differences across licensees and technologies that can be expected to affect how pervasive information asymmetries and problems of knowledge transfer are for a particular invention. Specifically, we study licensing across national boundaries as well as spin-off versus external licensees. While less relevant in the U.S. context, licensing to foreign firms is a pertinent issue in the smaller and more open European economies, which has received little prior attention in prior research. We also contribute new evidence to the unresolved issue of how effective inventor spin-offs are as commercializers of technologies from public research. Second, we investigate the effects of technology characteristics on the effectiveness of license-based technology transfer. In this context, we focus on the role of patent protection, inventor seniority and collaborative research. We use both the incidence and the level of royalties as measures of successful commercialization, also taking into consideration that nonrandom selection into licensing by different types of licensees may affect commercialization outcomes.

Our analysis indicates that even though information asymmetries and the difficulty of transferring non-codified knowledge are critical in shaping the success of license-based technology transfer from public research, they cannot fully explain the empirical patterns. Technologies licensed to foreign firms are less often commercialized, but this may reflect selection effects. Inventor spin-offs are no less successful in commercializing academic inventions than established firms even though they presumably are less well endowed with capabilities and complementary assets. Inventor seniority enhances the chances of technologies to be licensed, as does the presence and scope of patent protection. In contrast, patented inventions are less likely to yield successful commercial products. Overall, we find that with the exception of licensing to spin-offs, both the likelihood of finding a licensee and the likelihood of successful commercialization have fallen over the 25-year period under investigation.

The paper is structured as follows. The next section discusses how information asymmetry and knowledge transfer are relevant for license-based technology transfer from 
public research. In section 3, testable hypotheses about the effects of licensee and technology characteristics on licensing and successful commercialization are derived from the theoretical discussion. Section 4 provides background information on the technology transfer activities of the Max Planck Society, while section 5 describes the data and methodology of the empirical analysis. Results are presented in section 6 and discussed in section 7.

\section{Technology transfer through licensing of academic inventions}

Inventions by scientists in public research often provide the foundations of commercially viable innovations. Some academic inventions are made as joint products of research activities (think of instrumentation or lab equipment first used for the researcher's own use). In other cases, research results can both be published in a scientific journal and applied commercially (for example, “patent-paper pairs” related to the same findings are widespread in the life sciences; cf. Murray and Stern, 2007). In the Bayh-Dole-like institutional setting that is increasingly adopted also outside the U.S. (Lissoni et al., 2008) academic inventions have to be disclosed to the scientist's employer and become its property. If they are to be used for commercial purposes, prospective innovators have to obtain a license, even if they are identical to the original inventors. Most universities and public research organizations have established technology transfer offices (TTOs) that organize the protection of their IPRs and actively market their inventions.

Not only are academic inventions directly linked to current science, they also tend to be at an early stage of development. The technology to be commercialized has often not advanced beyond the proof-of-concept or prototype stage (Jensen and Thursby, 2001). Accordingly, licensees need to engage in substantial further development efforts to obtain a marketable product. Successful commercialization often hinges on the continued involvement of the academic inventor (Agrawal, 2006). The combination of being science-based and earlystage gives rise to at least three kinds of difficulties for the licensing and commercialization process: uncertainty, information asymmetry, and the need to transfer uncodified knowledge.

Like all inventions, university technologies cannot always be turned into successful products in the marketplace. Potential innovators obtaining licenses for technologies from public research face substantial uncertainty as to whether (i) they will be able to develop a functioning product, (ii) they will do so faster than potential competitors, and (iii) the product 
will be sufficiently successful with customers to justify the costs of licensing and development.

Problems of asymmetric information further complicate innovation activities based on technology transfer from public research (Gallini and Wright, 1990). As opposed to technologies developed in-house, potential licensees of academic inventions lack in-depth knowledge of the underlying research. This limits their ability to evaluate the commercialization prospects of the invention. At the same time, licensees typically have better knowledge of the markets for the prospective products than the inventor or the TTO representing her. To some degree, these problems of asymmetric information can be reflected in the design of licensing agreements and the payment schemes they provide for (Jensen and Thursby, 2001; Lowe, 2006). Effective IPRs, reputation, and trust based on prior collaboration and/or cultural proximity may further help overcome problems stemming from asymmetric information (cf., e.g., Granovetter, 1985; Shane and Stuart, 2002; Mora-Valentin et al., 2004). However, there is no guarantee that a licensing agreement can be concluded successfully in the presence of substantial asymmetric information. Typically, at best a few potential licensees exist for a particular technology, and licensing is based on small-numbers bargaining.

Asymmetric information arises as a problem in negotiating licensing agreements because both parties have incentives to withhold information, as this may increase their share in future innovation rents. However, even if both parties faithfully try to share their knowledge (for example, after a licensing agreement providing for sales-based royalties is entered into so that inventors have an interest in successful commercialization), substantial obstacles in communicating this knowledge typically have to be overcome. They derive from the nature of the relevant knowledge, which tends to be complex and imperfectly codified.

Agrawal (2006) argues that academic inventions often draw on multiple fields of knowledge. Potential licensees are unlikely to have substantial prior knowledge in all these fields. Accordingly, their absorptive capacities (Cohen and Levinthal, 1990) may be insufficient to fully understand information related to the invention, even if the inventor and/or the TTO disclose all their knowledge. In addition, relevant elements of that knowledge may be non-codified (even if they would in principle be codifiable; in which case they can be characterized as "latent” (Agrawal, 2006; cf. also Cowan and Foray, 1997)). For example, knowledge that the inventor gained from failed and therefore unreported experiments may frequently be inaccessible for an external licensee. Engaging the inventor in the further development process after concluding a licensing agreement may enable the licensee to draw 
on the inventor's non-codified knowledge (Agrawal, 2006). Whether inventor engagement is feasible and effective will depend on the inventor's willingness to cooperate as well as the quality and scope of her non-codified knowledge. The inventor's willingness to cooperate may in turn depend on the proximity, familiarity and type of the licensee.

The potential impact of licensee characteristics on the chances of successful commercialization clearly goes beyond their ability to secure the inventor's support. Firms differ in their dynamic capabilities of integrating new technologies, which derive from the firms' prior activities and competences (Teece et al., 1997). Particularly in younger and smaller firms, capabilities may also be critically affected by the pre-entry experience of the founder(s) as well as key employees (Helfat and Lieberman, 2002). In the present context, there may be substantial differences in the kind and richness of capabilities possessed by external licensees, which are typically established firms active in a variety of markets related to the licensed technology, relative to inventor spin-offs that tend to be younger and smaller, but also more intimately familiar with the scientific background of the licensed invention. In addition, external licensees are more likely to command substantial under-utilized complementary assets enabling them to benefit from innovation (Teece, 1986). They are also more likely to license inventions for primarily strategic reasons, i.e. to block competitors from the access to the underlying technology or to enhance their negotiation position in contexts of “patent thickets” (Shapiro, 2000).

While some degree of uncertainty about innovative success is irreducible, information asymmetries and communication problems in knowledge transfer are not equally pronounced in all technology licensing and commercialization. We expect them to vary across types of licensees as well as characteristics of the inventions. In the next section we derive hypotheses addressing these differences. The hypotheses are then tested empirically.

\section{Hypotheses}

Both information asymmetries and problems of knowledge transfer can be expected to vary with the cognitive "distance” (Nooteboom, 1999) between licensor (the academic inventor represented by her employer's TTO) and licensee. This distance is plausibly related to observable characteristics of both the licensee and the technology, which may therefore affect the likelihood that a licensing agreement is concluded and, if so, the invention is successfully commercialized. 


\subsection{Likelihood of licensing}

We consider differences in the nature of licensees along two dimensions: domestic versus foreign licensees, and inventor spin-offs versus external licensees. As regards the first dichotomy, information asymmetries are expected to be more pronounced in licensing negotiations across national boundaries. Information is harder to obtain for foreign licensees, particularly if they do not come from countries speaking the same language, and the design and monitoring of contracts is more difficult internationally. In addition, patents on the target technology may not have been obtained in the county of the potential foreign licensee, exposing it to an enhanced risk of imitation by competitors. In contrast, information asymmetry is minimized if a technology is licensed to a spin-off organized by its inventor(s).

The additional complications faced in licensing negotiations with foreign firms (as compared to domestic firms) and external licensees (as compared to inventor spin-offs) may be mitigated by characteristics of the technology to be licensed. Our data allow us to investigate three aspects of the technology: the presence and scope of patent applications related to the invention, the seniority of the inventor(s) affecting their reputation and possibly the quality of the invention, as well as whether or a technology is based on prior collaborative research between the inventor(s) and a private-sector firm.

Patents related to an academic invention provide a strong signal that the invented technology conforms to a given standard of novelty, usefulness and non-obviousness. This should enhance the likelihood that a technology is licensed. The value of this signal is expected to be larger when information asymmetry is more pronounced. Given the above considerations, we conjecture that this is the case for foreign licensees (compared to domestic ones) as well as for external licensees (compared to inventor spin-offs). The latter conjecture is in line with previous arguments suggesting that spin-off licensing might be a solution of last resort when attempts to find an external licensee have failed (Shane, 2002). Spin-off licensing would then be expected particularly when IPR protection is weak. Finally, patents enhance the strategic value of a technology in blocking competitors' market access or in negotiating access to complementary technologies, which presumably is more relevant to external licensees already active in related markets.

Following this line of reasoning, we conjecture the following relationship between patents and the likelihood of licensing a technology to different types of licensees:

Hypothesis 1a: The likelihood that an invention is successfully licensed is enhanced by the presence and scope of patents related to the invention. 
Hypothesis 1b: Patents have a stronger effect on the likelihood of licensing to a foreign firm than on the likelihood of licensing to a domestic firm.

Hypothesis 1c: Patents have a stronger effect on the likelihood of licensing to an external licensee than on the likelihood of licensing to an inventor spin-off.

We furthermore expect that licensing is affected by the time that a potential licensee learns about a nascent academic invention. Collaborative inventions based on joint research projects with private-sector partners appear particularly relevant in this context. Industry involvement at an early stage of research is likely to mitigate information asymmetries and problems of knowledge transfer. Joint research projects with industry partners presuppose some relevant prior knowledge of the industry partner, and ongoing communication of knowledge between both partners. They should therefore increase the industry partner's capability to evaluate the potential of inventions made in the project. If their assessment of the technology is low, industry partners may withdraw from cooperations even before inventions are arrived at, which should increase the average quality of inventions based on collaborative research. In addition, familiarity with the inventor helps build trust, enhancing the industry partner's willingness to close a licensing deal in the absence of fully symmetric information. Since the importance of collaboration should increase with the extent of information asymmetry, foreign and external licensees should benefit more than domestic licensees respectively spin-offs. These considerations lead us to the following hypotheses:

Hypothesis 2a: Academic inventions from collaborative research with industry partners are more likely to be licensed than other inventions.

Hypothesis 2b: Prior collaboration has a stronger effect on the likelihood of licensing to $a$ foreign firm than on the likelihood of licensing to a domestic firm.

Hypothesis 2c: Prior collaboration has a stronger effect on the likelihood of licensing to an external licensee than on the likelihood of licensing to an inventor spin-off.

As pointed out by Lowe (2002), the expected positive effect of collaborative research on the likelihood of licensing might be mitigated if in the process of collaboration industry partners acquired sufficient knowledge of the invention to render subsequent licensing unnecessary. However, this presupposes that the firm is able to design its innovation around the public partner's intellectual property rights, or that the public partner is unable to enforce them. We therefore expect that the positive effect of collaboration more than compensates for 
the negative effect suggested by Lowe. Furthermore, if Max Planck researchers predominantly collaborated with domestic incumbents, composition effects might dampen the differences across licensee types conjectured in Hypotheses 2b and 2c.

Finally, we expect that inventor seniority affects the likelihood of concluding a licensing agreement as well as the probable type of licensee. Substantial prior empirical research finds positive correlations between inventive output and the quantity and quality of research output at the level of individual academic inventors (e.g., Azoulay et al., 2009; Breschi et al., 2008; Buenstorf, 2009). Seniority therefore signals invention quality to potential licensees, thus increasing the willingness of potential licensees to enter into a contractual agreement. The value of the signal provided by seniority should be largest when information asymmetry is strong, i.e. in the cases of foreign and external licensees. If negotiations are mediated by a technology transfer office (as is the case in our empirical sample), it is likely that senior scientists have more influence on their employer institution than more junior ones. This may further increase the likelihood of a successful licensing agreement. We accordingly conjecture:

Hypothesis 3a: Technologies (co-) invented by senior scientists are more likely to be licensed than those by more junior researchers.

Hypothesis 3b: (Co-) invention by senior scientists has a stronger effect on the likelihood of licensing to a foreign firm than on the likelihood of licensing to a domestic firm.

Hypothesis 3c: (Co-) invention by senior scientists has a stronger effect on the likelihood of licensing to an external licensee than on the likelihood of licensing to an inventor spin-off.

\subsection{Commercialization of licensed technologies}

Not only the likelihood of concluding a licensing agreement, but also the likelihood of successfully bringing the technology to the market can be expected to differ according to licensee and technology characteristics. Post-agreement inventor involvement in the development efforts has been demonstrated to increase the likelihood of successful commercialization (Agrawal, 2006). If a royalty-based contract has been concluded, bringing the product to the market is the mutual interest of licensor and licensee (Jensen and Thursby, 2001). Accordingly, academic inventors harm themselves if they do not cooperate in postlicensing development efforts. They may nonetheless exert less effort than would be called for because of competing demands on their time, particularly when primarily motivated by the reward mechanisms of open science (Dasgupta and David, 1994; Stephan, 1996). Equally 
important for successful commercialization appears their ability to communicate their knowledge to the licensee. Both the personal cost and the effectiveness of inventor engagement are expected to differ with licensee and technology characteristics. We conjecture that these differences affect the likelihood that a licensed academic invention can be turned into a commercial success.

In the case of foreign licensees, geographic distance and language barriers complicate post-agreement inventor involvement. Traveling is more costly in terms of time and money, and the transfer of non-codified knowledge (which presupposes frequent face-to-face interaction) is possibly less effective if national boundaries have to be crossed. We therefore predict the following:

Hypothesis 4: Inventions licensed to foreign firms are less likely to be commercialized successfully than inventions licensed to domestic firms.

Spin-off licensing facilitates inventor involvement. Transfer of non-codified knowledge to the spin-off firm is enhanced by personal migration of the inventor and/or associates from her laboratory to the new firm. Even though senior Max Planck scientists do not normally enter the active management of spin-offs (co-) founded by them (cf. Buenstorf, 2009), inventor-founders nonetheless have strong incentives for engaging in the spin-off's development activities, and they typically assume at least consulting positions in the new venture. Staff members of the spin-off may moreover be able to informally contact their prior co-workers in the inventor's laboratory when in need of additional knowledge.

Commercialization activities by spin-offs are expected to benefit from the facilitated transfer of non-codified knowledge. In addition, given a smaller product portfolio, spin-off survival is typically more dependent on specific technologies than survival of established firms. Spin-offs consequently face stronger incentives for successful commercialization (Lowe and Ziedonis, 2006). They are less likely to license a technology for purely strategic reasons (i.e., to prevent others from using it or use it as a bargaining tool vis-à-vis competitors). Based on these considerations, we predict the following:

Hypothesis 5: Inventions licensed to inventor spin-offs are more likely to be commercialized successfully than inventions licensed to external licensees. 
Effective knowledge transfer alone clearly is not sufficient to ensure successful commercialization. Existing evidence on the commercialization performance of spin-offs is inconclusive. Counter to Hypothesis 5, Shane (2002) stipulates that spin-offs are inferior in commercialization because they lack the required complementary assets (Teece, 1986). However, for their sample of licensed inventions from the University of California system, Lowe and Ziedonis (2006) find neither lower commercialization odds nor lower licensing income for spin-off licensees. This indicates that Shane's argument may be of secondary importance, lending support to the prediction of Hypothesis 5 and the stipulated relevance of differences in the ease of knowledge transfer for the two types of licensees.

Turning to technology characteristics, the relationship between patent protection and commercialization of an academic invention is ambiguous. On the one hand, the process of writing a patent application forces the inventors to codify substantial parts of the knowledge underlying the invention. This would be expected to help subsequent licensees turn the invention into a commercially successful product. At the same time, the above considerations regarding strategic patenting to prevent competitors from exploiting an invention or to gain negotiating power in patent thickets suggest that patented technologies may be less likely to be commercialized. Based on the assumption that the challenges of knowledge transfer are more relevant for the commercialization of academic inventions than strategic patenting, we predict the following:

Hypothesis 6: The presence and scope of patent protection related to an invention is positively related to its likelihood of commercialization.

In the case of collaborative research, knowledge transfer between inventor and licensee is facilitated by absorptive capacities and shared understandings developed in the prior research activities. Pre-existing familiarity with the technology also provides the licensee with a speed advantage, enhancing the odds of successful commercialization (Markman et al., 2005). In addition, licensees that were involved in collaborative research leading to the licensed technology have superior information about this technology. This enhances their ability to decide whether to license, which increases the likelihood that licensed inventions can also be commercialized (the selection effect already suggested above). We accordingly expect a positive effect of prior collaboration on commercialization: 
Hypothesis 7: Inventions from collaborative research with industry partners are more likely to result in commercially viable products and processes than others.

Agrawal (2006) studies a similar issue in the U.S. context, using a sample of 124 licensed inventions from MIT’s mechanical engineering and electrical engineering / computer science departments. He finds positive effects for sponsored research both on the likelihood of successful commercialization and on the level of revenues generated thereby. Neither effect is statistically significant, however.

Finally, the successful commercialization of a university invention may also depend on the seniority of the inventor(s). As with patents, two contravening effects of inventor seniority on the commercialization odds of academic inventions seem plausible. On the one hand, as argued above, prior research indicates that more successful researchers may also have inherently superior inventions, so seniority would be expected to be related to higher commercialization odds and higher royalty income. On the other hand, the more senior an inventor is, the higher are her opportunity costs of post-agreement involvement in the licensee's development efforts. Ceteris paribus, senior scientists are therefore expected to spend less time on their inventions, which will lower the likelihood of successful commercialization. This might be particularly salient for inventions licensed to external licensees, as senior scientists may be more willing to spend time with their spin-off firms, the success of which is more relevant both to their income and their reputation. We will explore this conjecture below. In general, we expect that the quality effect of seniority outweighs the opportunity cost effect. This assumption informs our final hypothesis:

Hypothesis 8: Technologies (co-) invented by senior scientists are more likely to be commercialized than inventions by more junior scientists.

\section{Technology transfer at the Max Planck Society}

Public research in Germany is characterized by a unique division of labor between universities and a variety of non-university public research organizations (PROs). Among the latter, the Max Planck Society is the largest one focussing on basic research. It currently employs some 4,700 researchers and receives almost 80 per cent of its budget from public, institutional funding (Max Planck Society, 2008). The mission of the Max Planck Society is 
to complement the university system by taking up large-scale, interdisciplinary, or particularly innovative activities that are out of reach for individual universities or do not fit their organizational structure. To this purpose, it has established 80 individual Max Planck Institutes that are dispersed all over the country (plus three institutes located abroad) and cover the full spectrum of the sciences and the humanities. The institutes are organized into three sections: the biomedical section, the chemistry, physics and technology section, as well as the humanities and social sciences section.

The Max Planck Society's internal organization is unique. Its basic strategy is to put its highest-level researchers, the Max Planck directors, in a particularly autonomous and powerful position. Their mission is research-oriented, with substantial long-term, institutional funding. New directors are recruited among the most successful researchers of domestic and foreign universities. The Max Planck Society currently has some 270 active directors.

Until 2002, inventions made by the Max Planck Society's employees were treated differently from those of German university researchers. Just as the employees of privatesector firms, employees of the non-university PROs including the Max Planck Society have always been subject to the Arbeitnehmererfindungsgesetz. This law on employee inventions mandates that employees must disclose all inventions to their employer, and assigns the property rights in these inventions to the employer. ${ }^{1}$ As a consequence, the Max Planck Society can claim ownership in the invention, in which case it applies for patents (for suitable technologies) and organizes the negotiation and administration of licensing agreements. In the case of successful commercialization, the inventor receives 30 per cent of all revenues from licenses and patent sales.

Our empirical analysis exploits the fact that the Max Planck Society owned the inventions of its researchers already before 2002. We use information about inventions and licensing agreements provided by Max Planck Innovation GmbH, the Max Planck Society’s legally independent technology transfer subsidiary. Max Planck Innovation was organized in 1970, originally under the name Garching Innovation. After some early attempts of constructing and marketing prototypes based on Max Planck inventions, for the past three decades it has focused on patenting and licensing activities. Disclosure of inventions is actively solicited at the individual institutes. Patents are applied for if the invention is patentable and considered sufficiently promising, even if no licensee for the technology has

\footnotetext{
${ }^{1}$ In contrast, before the so-called Hochschullehrerprivileg or "professors' privilege” was abolished in 2002, university researchers were exempt from the law and retained the intellectual property in their inventions (cf. von Ledebur et al., 2009).
} 
been identified. ${ }^{2}$ Technologies are marketed to both domestic and foreign firms. Systematic support and counseling of spin-off activities was taken up in the early 1990s, and spin-off numbers have strongly increased since then. Overall licensing income contributes about 1 per cent to the Max Planck Society’s annual budget (Max Planck Society, 2008).

\section{Dataset and econometric approach}

\subsection{Sources}

This study is primarily based on two sets of data made available by Max Planck Innovation. The first dataset contains all inventions disclosed by Max Planck researchers from the early 1970s to $2004 .^{3}$ In total, it encompasses 3,012 inventions. 1,885 resulted in at least one patent application. ${ }^{4}$ The database includes the title of the invention, names and institute affiliations of the inventors, day of disclosure and (if eligible) patent application, as well as information regarding further use of the invention.

We matched these data with a second dataset assembled from Max Planck Innovation's licensing agreements. 864 inventions (614 patented inventions) have been licensed, and because non-exclusive contracts may have multiple licensees, there are in total 1,172 licensing agreements. A substantial number of licensing agreements cover more than a single invention. These were treated as individual contracts for the corresponding inventions because we are interested in the commercial potential of individual inventions. Payments from these agreements (if any) were split equally between the involved inventions. We control for this "license bundling" in the subsequent empirical analysis.

For each contract, information is available about the licensee name and address, the dates when the agreement was concluded and (possibly) terminated, contractual arrangements regarding fixed fees and royalties, as well as actual dates and amounts of payments as of 2007. As academic inventions are mostly licensed within a few years after their invention, restricting the sample to pre-2005 inventions while including payments through 2007 minimizes right censoring issues. Max Planck technologies are similar to other academic

\footnotetext{
${ }^{2}$ In this regard, Max Planck Innovation's patenting policy thus appears to be closer to that of the MIT than that of the UC system (cf. Shane, 2002; Lowe and Ziedonis, 2006)

${ }^{3}$ Researchers employed on a scholarship basis, mostly Ph.D. students and international postdocs, are not subject to the German law on employee inventions (Arbeitnehmererfindungsgesetz). To the extent that these individuals made inventions without other Max Planck researchers being involved, they do not show up in the data.

${ }^{4}$ In 141 cases, no patent information was found even though the inventions database identified them as patented. We suspect that most of these cases reflect cancelled applications. They are treated as not being patented in the subsequent analysis.
} 
inventions in that payments (in particular, royalties) are extremely skewed. A single Max Planck invention in the sample accounts for more than $75 \%$ of the overall returns.

Patent data are used to control for heterogeneity in the quality of inventions. Our primary proxy for patent quality is the number of members in the patent family. It indicates the geographical scope of the IPR protection sought by the patent application and is a widely accepted measure of patent quality (Harhoff et al., 2003). In addition, we include a dummy variable indicating applications in the three most important economic regions. These "triadic" patent families indicate applications at the European Patent Office and its Japanese and U.S. counterparts. We also experimented with the number of IPC classes and granted patents in the family as quality indicators, but they were less predictive and so we did not pursue these experiments further. To obtain the patent information, we conducted a patent family search in Depatisnet, the publicly available patent search site of the German Patent Office (DPMA), using the patent applications listed in the Max Planck Innovation invention database as our point of departure. This yielded some 10,000 documents for all inventions since the early 1970s. These documents were stored in a separate database preserving the original patent family structure. Subsequently, they were linked to the invention dataset.

We restrict our empirical analysis to the 2,392 inventions disclosed in or after 1980. Earlier inventions are excluded for three reasons. First, the earliest entries in the inventions dataset are not consistently inventions by Max Planck researchers, since at the time Garching Innovation was offering its services to a variety of other PROs and even some commercial firms, whose inventions then show up in our data. Second, the quality of the earliest data was below that related to later inventions. Third, systematic support of spin-off activities out of the Max Planck Society only began around 1990, and even though spin-off activities can be found before, they were of little import in the earliest years of the data. Another 141 inventions had to be dropped because of non-availability of data. Accordingly, the final dataset used in the empirical analyses contains 2,251 inventions, 1,382 of which have been patented (Table 1a).

\subsection{Variables}

Three dependent variables are used in the subsequent models. First, we study whether or not an invention was licensed. Licensing can readily be inferred from the existence of a licensing agreement. 721 (32 per cent) of all inventions disclosed after 1980 have been included in a licensing agreement. This number is comparable to U.S. institutions studied before. For example, Lowe and Ziedonis (2006) study 734 licensing deals closed by the UC system 
between 1981 and 1999. Second, we are interested in the factors conditioning successful commercialization. While this information is not directly contained in the data, we derive it from the existence of positive royalty payments. Of course, this restricts the sample for studying commercialization to those inventions where licensing agreements provided for royalty payments (not only fixed fees). In the post-1980 sample, there are 729 cases of this kind, of which 365 (50 per cent) have resulted in positive royalties (Table 1b). Third, we are concerned about the distribution of returns from these contracts. We have data on yearly payments from individual contracts until 2007. Since they are highly skewed we analyze the log of cumulative royalty payments, eliminating outliers in some analyses as a robustness check.

As central explanatory variables, the analysis uses four indicator variables identifying, respectively, foreign licensees, spin-off licensees, collaborative inventions, and senior inventors. To study effects of international licensing, licensees were classified into domestic versus foreign according to the postal address given in the data. Accordingly, German branches and subsidiaries of foreign companies are classified as German licensees. This is in line with our primary interest in potential difficulties arising from information asymmetries and the transfer of non-codified knowledge, which we expect to depend more on the licensee's physical location than on whether or not the licensee is foreign-owned. International license agreements are widespread in the Max Planck Society. Of the 1,033 $(729)^{5}$ license agreements for inventions disclosed since 1980, 349 (241) are with foreign licensees. Spin-offs among the licensees were identified on the basis of Max Planck Innovation's spin-off database. There are 236 (198) cases of licenses to spin-offs in the sample.

Collaborative inventions are identified on the basis of patent applications. We define as collaborative all inventions that were not exclusively assigned to the Max Planck Society (i.e., those assigned either to the Max Planck Society and a private-sector firm, or exclusively assigned to a private-sector firm). Their total number is 133 (73). ${ }^{6}$ Finally, senior scientist involvement is proxied by technologies (co-) invented by one or (in rare cases) several Max Planck directors, which is justified by the distinctive position directors have in the Max Planck hierarchy. We identified the directors using published sources (Henning and Ullmann,

\footnotetext{
${ }^{5}$ Numbers in parentheses refer to the subset of agreements providing for royalty payments that were actually analyzed to test the hypotheses related to commercialization.

${ }^{6}$ Patent ownership is a restrictive measure of collaborative invention (Fontana and Geuna, 2009), which is reflected by the comparatively small number of collaborative inventions we thus identified. We alternatively considered using information about collaboration from the Max Planck Innovation invention database. However, since the database is updated regularly and we do not have information about when the collaboration information was entered, we did not use it in the analysis based on endogeneity concerns.
} 
1998; Max Planck Society, 2000) and information provided by the Max Planck Society's human resource department. We identify 381 (279) cases of director involvement.

A set of control variables is used. Existence and quality of patents related to an invention is proxied by patent application and patent family size. Moreover, we apply a dummy variable for "triadic" patents (patent application in the EU, the U.S. and Japan) indicating inventions that are perceived to be valuable worthy of broad protection. We further control for discipline-specific factors with a dummy variable denoting inventions from the biomedical section. This dummy is zero for inventions from the chemistry, physics and technology section. ${ }^{7}$ Controls are also included for the top five institutes in terms of the number of disclosed inventions. Time effects are captured by an integer variable denoting the year of disclosure of the invention and starting with " 0 " in 1980 (the first year of our analyses). Finally, in the analyses of commercialization, we also include dummies denoting all licensing agreements involving repeat licensees that show up more than once in the full database, as well as cases where a "bundle" of multiple inventions was licensed to the same licensee (cf. the above discussion). Descriptive statistics and correlations between the independent variables are given in Tables 2a-b through 4a-b.

\subsection{Methods}

Multinomial logit models are employed to analyze the likelihood that a given invention was licensed to a specific type of licensee. We estimate two sets of models, with the alternative outcomes being, respectively, licensing to a domestic versus foreign licensee, or licensing to an external licensee versus an inventor spin-off. (No licensing is the reference outcome in both sets of models.)

The likelihood of successful commercialization is studied in three steps. First, we estimate a set of logit models with commercialization as the dependent variable, using the set of licensing agreements as our sample, and estimating standard errors clustered by invention to account for multiple licensing. As noted above, commercialization is defined as the existence of positive royalty payments. Obviously, this restricts the sample to the subset of licensing agreements that contain provisions providing for royalty payments. Second, we also analyze the commercial success of licensed technologies using the amount of royalties as the dependent variable. Since royalties are highly skewed we employ natural logarithms of this

\footnotetext{
${ }^{7}$ There are a handful of inventions that cannot be assigned to one of these sections, mostly because they were disclosed by staff of the Max Planck Society's general administration or have been assigned to an institute outside the Max Planck Society (e. g., the Helmholtz Society). These inventions have been dropped from the analysis.
} 
variable. Royalties are censored at zero, which we take into consideration by estimating Tobit models.

A shortcoming of both approaches is that they do not account for selection effects: Technologies licensed to different kinds of licensees may differ in their characteristics, and these differences may affect their subsequent commercialization odds. Our analysis of licensing indicates that there are indeed substantial differences between the technologies licensed to different kinds of firms, which suggests that selection into the different kinds of licensing contracts (domestic versus foreign, spin-off versus external) is not random.

To test whether differences in the commercialization likelihood of different types of licensees are due to differences in observables affecting selection into licensee types, we interpret specific kinds of licensing agreements as treatments, and estimate how being treated affected the commercialization likelihood using propensity score matching (Rosenbloom and Rubin, 1983; Heckman et al., 1998; cf. also Sianesi, 2001; Wooldridge, 2002, ch. 18). Specifically, two propensity score matching estimators are employed: in the first one, the treatment consists in being licensed to a foreign licensee. In the second one, licensing to a spin-off is the treatment.

The intuition underlying propensity score matching is as follows. In non-experimental data, for each observation only one outcome (here: commercialization success) is observed. If $Y_{\mathrm{i} 0}$ denotes observation i's outcome without treatment, $Y_{\mathrm{i} 1}$ denotes observation i's outcome with treatment, and $T \in\{0,1\}$ denotes treatment, we would like to know the treatment effect $Y_{\mathrm{i} 1}-Y_{\mathrm{i} 0}$, but can only observe one of the two outcomes. If selection into treatment is nonrandom, the effect of treatment on the outcome cannot be separated from the selection effect in the data.

Propensity score matching uses the available information on individual observations to generate a counterfactual control group from the untreated observations, such that differences in observable characteristics are minimized between the treated observations and the members of the control group. The basic approach is to calculate the probability of receiving treatment for each observation based on its observable characteristics, using probit or logit models. This conditional probability is the propensity score, which is then used for matching the treated observations to similar non-treated ones. Under the assumption that selection into treatment only depends on observables, the average effect of treatment can then be estimated at the population level. Specifically, both the average treatment effect (ATE), $\mathrm{E}\left(Y_{\mathrm{i} 1}-Y_{\mathrm{i} 0}\right)$, and the average treatment effect on the treated (ATT), $\mathrm{E}\left(Y_{\mathrm{i} 1}-Y_{\mathrm{i} 0} \mid T=1\right)$, can be estimated. 
Various propensity score-based matching methods have been proposed. When large samples of non-treated observations are available, each treated observation can be matched to an "identical twin," i.e. a non-treated observation that is very similar in its propensity score, and the outcomes of both observations are then compared. Alternatively, each treated observation can be matched to a weighted average of untreated observations, where the weights are determined by how similar the propensity scores of the untreated observations are to that of the treated one. We adopt the latter approach below. We report results obtained by estimating propensity scores with logit models, using a Gaussian kernel for matching, where the weights of the untreated observations follow a normal distribution around the propensity score of the respective treated one. The estimations were performed using the psmatch2 routine for Stata 9.0 (Leuven and Sianesi, 2003).

\section{Results}

\subsection{Likelihood of licensing}

Models 1-3 (Table 5) analyze how licensing to domestic versus foreign licensees is related to characteristics of the technology as well as its inventors, and the corresponding Models 4-6 (Table 6) analyze the same issue for inventor spin-off versus external licensees.

We find that patented inventions are more likely to be licensed to either type of licensee, and that among the patented inventions family size enhances the likelihood of licensing, both of which is consistent with Hypothesis 1a. Counter to Hypothesis $1 \mathrm{~b}$, the estimated effects of patent protection are very similar for domestic and foreign licensees. As regards Hypothesis 1c, we even find that the likelihood of licensing by spin-offs is more strongly related to the presence of patent applications ( $p<0.002$ in Models 4 and 5 ) than the likelihood of licensing to external licensees. This runs counter to our expectations. A possible explanation might be that ambitious inventor spin-offs are critically dependent on external financing by venture capitalists and access to capital is facilitated by a strong IPR position. Our findings suggest that this effect may be stronger than the conjectured role of information asymmetries.

Since our proxy for collaborative inventions is patent-based, the conjectured relationship to the likelihood of licensing can only be tested for the restricted sample of patented inventions. The results indicate that information asymmetry may not be the major factor explaining differences between collaborative and other inventions, as there are no 
significant positive effects of the collaboration variable on licensing of any type. At the same time, counter to the "skimming" argument put forward by Lowe (2002) we find no evidence that collaborative inventions in general are less often licensed than others. One possibility is that both effects compensate each other: selection enabled by better information may be counteracting the effect of reduced difficulty in negotiating, and only the most promising technologies from collaborative research are actually licensed. We furthermore find that collaborative inventions are less likely to be licensed to foreign firms, which may reflect composition effects in the partners of collaboration. In line with Hypothesis 3c, collaboration affects licensing by external licensees more favorably than by spin-offs (for spin-offs a marginally significant negative coefficient is estimated; and the difference between the coefficients is significant at $\mathrm{p}<0.02$.).

Inventor seniority is positively related to the likelihood of licensing across all licensee types, consistent with Hypothesis 3a. As regards the nationality of licensees, differences in the effects of seniority are small and insignificant, while counter to Hypothesis 2c seniority seems to play an even bigger role for spin-offs than for external licensing. This may reflect a stronger willingness of senior researchers to engage in entrepreneurial activities compared to licensing to outsiders.

Finally, two regularities related to the control variables are noteworthy. First, later inventions are less likely to be licensed both to domestic and to foreign licensees. This seems to reflect higher aspiration levels of potential licensees and/or decreasing average quality of inventions. An alternative explanation might be right censoring issues, but experiments replacing the time variable by a set of three cohort dummies found that inventions disclosed 1990-97 already were less likely to be licensed than earlier ones. (The results are available from the authors.) We also see that spin-off licensing is gaining in importance over time, which resonates with what we know about academic spin-offs from the Max Planck Society as well as German universities and PROs more generally. Second, inventions from the biomedical section are more likely to be licensed to foreign licensees, possibly reflecting more developed markets for technology in this field and/or the sectoral structure of the German economy. While spin-offs also appear more likely to license biomedical inventions than external licensees, this difference is not significant and further decreases with the inclusion of institute controls and patent quality indicators. 


\subsection{Likelihood of commercialization}

Three alternative approaches are employed to identify potential factors influencing the likelihood that licensed inventions are successfully commercialized. Odds of commercialization are first analyzed using logit models (Models 7-12 in Table 7), with successful commercialization measured by an indicator variable denoting licensing agreements that led to positive royalty payments. Second, the logged amount of royalties is adopted as an alternative measure of commercial success (Models 13-18 in Table 8.) We finally consider potential effects of non-random selection into licensee types using propensity score matching (Table 9).

As predicted by Hypothesis 4, the results of the logit models indicate that foreign licensees are significantly less likely to commercialize a licensed technology. They thus lend support to the conjecture that international knowledge transfer causes problems hindering the successful development of university technologies. Less conclusive evidence is obtained for the level of royalty payments, where the variable denoting foreign licensees is significant only in Models 17 and 18 that are restricted to patented inventions and exclude outliers. Furthermore, propensity score matching (Model 19 in Table 9) indicates that selection may account for the lower commercialization chances of inventions licensed to foreigners. ${ }^{8}$ Without matching, the commercialization likelihood of technologies licensed to foreign firm is 7.9 percentage points lower than that of technologies licensed within Germany. Comparing the technologies licensed to foreigners with similar technologies licensed at home reduces this difference to 5.8 percentage points, which is not significantly different from zero. This suggests that the observable disadvantage of technologies licensed abroad is in part due to selection, while the remaining difference may not be systematic. ${ }^{9}$

All three methods do not yield evidence suggesting that spin-off licensees significantly differ from external licensees in their likelihood to commercialize inventions or in the level of royalties. We therefore reject Hypothesis 5, which predicted that due to easier knowledge transfer and/or stronger incentives spin-offs should be more successful commercializers. At the same time, we also do not find that spin-offs are inherently inferior to established firms as commercializers.

\footnotetext{
${ }^{8}$ To obtain propensity scores, a logit model for the likelihood of being licensed to a foreign licensee was estimated first. We use a specification similar to Model 10 but adding patent family size (set equal to zero for unpatented inventions) while excluding the non-predictive dummy for triadic patents. Kernel-based matching of treated and untreated observations was then adopted (cf. also section 5).

${ }^{9}$ If the whole population of licensed technologies is considered, the average effect of treatment is 13.6 percent, which is significant at the $5 \%$ level.
} 
Of all independent variables, the clearest pattern of evidence emerges for the patent variable. The dummy variable denoting inventions related to patent applications is sizable and strongly negative in all models, indicating that these inventions had lower commercialization chances than unpatented technologies. In contrast, the proxies for patent quality are nonpredictive throughout. As regards collaborative inventions, we obtain positive coefficient estimates for both commercialization likelihood and levels of royalties, but these are mostly only marginally significant at the $10 \%$-level.

The seniority variable denoting Max Planck directors among the inventors of a technology has no discernible impact on commercialization success. In light of the substantial effects of seniority found above in the analysis of licensing, we decided to probe its effect further, in particular allowing for the effect of seniority to differ between inventions licensed to spin-offs versus external licensees. To this purpose we replaced the overlapping dummy variables denoting spin-off licensees and director-inventors by three separate, nonoverlapping interactions denoting, respectively, director-inventions licensed to spin-offs, other inventions licensed to spin-offs, and director-inventions licensed to external licensees (Model 10). The results indicate that even with this more fine-grained classification, differences in commercialization chances relative to the control group of non-director inventions licensed to external licensees are not significantly different from zero. The largest difference is found between the two types of director-invented technologies, where those licensed to external licensees are marginally more likely to be commercialized than those licensed to spin-offs ( $p$ $<0.10$ ). However, in the other models using the same distinction (Model 12 restricted to patented inventions, as well as Models 16 and 18 studying levels of royalty), no systematic differences across the licensees of inventions by senior researchers can be identified.

Finally, it is worthwhile to point out that in all models, later inventions are systematically less often commercialized and yield systematically lower royalties than earlier ones. Again, we replaced the time variable by three cohort dummies to control for the possibility that the decline in commercial success is due to right censoring of the data. The (unreported) results show that in terms of commercialization likelihood, the first and second cohorts (pre-1990 and 1990-97 inventions) are more different than the second and the third, which would not be expected if the variation was mostly due to right censoring. Therefore, we cannot rule out that the difference in commercialization odds between older and younger inventions indeed reflects a decreasing trend in the commercial values of Max Plank inventions. 


\section{Discussion}

Technology transfer activities from public research are increasingly embraced by policy makers, the management of universities and PROs, and also by (many of) the researchers themselves. Public research is also highlighted as a key component of interactive innovation processes in the systems of innovation literature (cf. Lundvall, 1988; Nelson, 1993; Malerba, 2002). However, we only have limited micro-level evidence on the interrelations between public research and private-sector innovation, in particular with regard to countries outside the U.S. This evidence would be instrumental to better understand and govern science-based innovation activities.

We know that academic inventions are typically in an early development stage (Jensen and Thursby, 2001). As a consequence, they are not available "off the shelf” for private-sector licensees, but ongoing direct interaction and inventor engagement is crucial to turn them into commercially viable products. This characterizes technology "transfer" as an interactive process, which resonates with the evolutionary, non-linear conception of innovation processes (Kline and Rosenberg, 1986; Cohen et al., 2002; Nelson, 2004).

In the present article, we studied technology transfer through licensing of inventions from a major European non-university PRO, Germany’s Max Planck Society. Due to peculiarities in the treatment of academic inventions in Germany before 2002, data on the incidence and success of technology licensing from the Max Planck Society are available for an exceptionally long period of time. These data inform our econometric analysis, which covers the full population of Max Planck inventions and licenses for the 1980-2003 period and takes into consideration that only the selected subset of licensed technologies is actually at risk of being commercialized.

To guide the analysis, we derived a number of testable hypotheses using the notion of “cognitive distance” (Nooteboom, 1999) between academic inventors and private-sector licensees as our conceptual point of departure. When inventors know different things from what (potential) licensees know, the ensuing problems of asymmetric information may prevent the parties from agreeing on a mutually acceptable licensing agreement. We further conjectured that because the inventors' knowledge is not fully codified but partially tacit or at least "latent" (Agrawal, 2006), i.e. codifiable but not actually codified, problems of communication and knowledge transfer may ensue even when incentive problems have been solved. The larger the "distance” in the knowledge of inventors and (actual) licensees, the more difficult we would expect the commercialization of academic inventions to be. 
Our empirical results are consistent with a substantial impact of "cognitive distance" on licensing incidence and success. We find that inventor spin-offs are indistinguishable from external licensees both in their likelihood of commercializing academic inventions and in the level of royalties they generate from product sales. This suggests that deeper understanding of the technology by the inventor spin-off may compensate for expected disadvantages from inferior organizational capabilities as well as lacking complementary assets. It qualifies earlier arguments that spin-off licensing may be a second-best outcome (Shane, 2002).

We found that foreign licensees were less frequent than domestic ones. Prima facie evidence indicated they also were less successful as commercializers of academic inventions, even though this difference partially reflects non-random selection into licensing by foreigners and was found not to be systematic using propensity score matching.

Technologies (co-) invented by senior scientists are more likely to be licensed, while we find no evidence that they are less likely to be commercialized than those of less senior researchers. This suggests that the quality signal provided by inventor seniority effectively enhances the likelihood of concluding a licensing agreement. It moreover suggests that the signal is valid, as the higher likelihood of licensing does not lower the chances of success. Inventions based on collaborative research (narrowly defined by joint patent applications or patents owned by private firms) tend to be more successfully licensed, but our measure of collaboration restricts the sample to the patented inventions and the estimated coefficients are only marginally significant.

At the same time, some of our findings suggest that information asymmetry and knowledge transfer cannot fully account for the observable differences in licensing and commercialization. The role of patents is noteworthy in this regard. Both the existence of patent applications and their scope are related to a strongly higher likelihood that the technology is licensed, which is consistent with patents reducing the relevance of asymmetric information. However, counter to expectations, foreign licensing is not affected more strongly by patents than domestic licensing, whereas spin-off licensing is more strongly related to patents than external licensing. Even more surprisingly, inventions related to patents are less likely to be commercialized than others. These patterns suggest that patents play a more complex role than just reducing information asymmetry and facilitating knowledge transfer through partial codification. In particular, the apparent importance of patents for spin-off licensees may reflect that spin-off entrepreneurs need IPR to attract external financing.

The empirical analysis of license-based transfer activities from the Max Planck thus shows that the patterns of licensing and commercialization are complex. Further theoretical 
and empirical work is required to better understand the process through which academic inventions are turned into commercial success stories. Obviously, the generality of our results is limited because the analysis only covered a single organization, which moreover follows a dedicated mission to focus on basic research. However, the Max Planck Society was among the pioneers of IPR-based technology transfer in Europe, consistently subject to the BayhDole-like IPR regime that is increasingly adopted also for the governance of European university inventions. On the one hand, this institutional development toward the kind of IPR regime that underlies our results enhances their relevance. On the other hand, over time it will allow for an increasing number of studies to improve our knowledge about technology licensing, knowledge transfer and innovation based on public research. 


\section{References}

Agrawal. A. 2006. "Engaging the inventor: Exploring licensing strategies for university inventions and the role of latent knowledge.” Strategic Management Journal, 27: 6379.

Azoulay, P., W. Ding and T. Stuart. 2009. “The Impact of Academic Patenting on the Rate, Quality and Direction of (Public) Research Output.” Journal of Industrial Economics, 57: 637-676.

Bozeman, B. 2000. “Technology transfer and public policy: a review of research and theory.” Research Policy, 29: 627-655.

Breschi, S., F. Lissoni and F. Montobbio. 2008. "University patenting and scientific productivity: a quantitative study of Italian academic inventors.” European Management Review, 5: 91-109.

Buenstorf, G. 2009. “Is commercialization good or bad for science? Individual-level evidence from the Max Planck Society.” Research Policy, 38: 281-292.

Cohen, W. M. and D. A. Levinthal. 1990. “Absorptive capacity: a new perspective of learning and innovation.” Administrative Science Quarterly, 35: 128-152.

Cohen, W. M., R. R. Nelson and J. P. Walsh. 2002. "Links and Impacts: The Influence of Public Research on Industrial R\&D.” Management Science, 48: 1-23.

Cowan, R. and D. Foray. 1997. "The Economics of Codification and the Diffusion of Knowledge.” Industrial and Corporate Change, 6: 595-622.

Dasgupta, P. and P. A. David. 1994. “Toward a New Economics of Science.” Research Policy, 23: 487-521.

Fontana, R. and A. Geuna. 2009. “The Nature of Collaborative Patenting Activities.” Bocconi University, mimeo.

Gallini, N. T. and B. D. Wright. 1990. "Technology Transfer under Asymmetric Information.” RAND Journal of Economics, 21: 147-160.

Granovetter, M. 1985. "Economic Action and Social Structure: The Problem of Embeddedness.” American Journal of Sociology, 91: 481-510.

Harhoff, D., F. M. Scherer and K. Voper. 2003. "Citations, family size, opposition and the value of patent rights.” Research Policy, 32: 1343-1363.

Heckman, J. J.m H. Ichimura and P. Todd. 1998. "Matching as an Econometric Evaluation Estimator.” Review of Economic Studies, 65: 261-294. 
Helfat, C. E. and M. B. Lieberman. 2002. “The birth of capabilities: market entry and the importance of pre-history.” Industrial and Corporate Change, 11: 725-760.

Henning, E. and D. Ullmann. 1998. Wissenschaftliche Mitglieder der Max-PlanckGesellschaft zur Förderung der Wissenschaften im Bild. Berlin: Duncker \& Humblot.

Jensen, R. and M. Thursby. 2001. "Proofs and Prototypes for Sale: The Licensing of University Inventions.” American Economic Review, 91: 240-259.

Kline, S. J. and N. Rosenberg. 1986. “An Overview of Innovation.” In: R. Landau and N. Rosenberg (eds.): The Positive Sum Strategy: Harnessing Technology for Economic Growth. Washington DC: National Academy Press, pp. 275-305.

Leuven, E. and B. Sianesi. 2003. "PSMATCH2: Stata module to perform full Mahalanobis and propensity score matching, common support graphing, and covariate imbalance testing.” http://ideas.repec.org/c/boc/bocode/s432001.html.

Lissoni, F., P. Llerena, M. McKelvey and B. Sanditov. 2008. “Academic patenting in Europe: new evidence from the KEINS database.” Research Evaluation, 17: 87-102.

Lowe, R. A. 2002. "Entrepreneurship and Information Asymmetry: Theory and Evidence from the University of California.” Carnegie Mellon University, mimeo.

Lowe, R. A. 2006. "Who Develops a University Invention? The Impact of Tacit Knowledge and Licensing Policies.” Journal of Technology Transfer, 31: 415-429.

Lowe, R. A. and A. A. Ziedonis. 2006. "Overoptimism and the Performance of Entrepreneurial Firms.” Management Science, 52: 173-186.

Lundvall, B.-A. 1988. "Innovation as an Interactive Process: From User-Producer Interaction to the National System of Innovation.” In: G. Dosi, C. Freeman, R. Nelson, G. Silverberg and L. Soete (eds.): Technical Change and Economic Theory, London: Pinter, pp. 349-369.

Malerba, F. 2002. "Sectoral systems of innovation and production.” Research Policy, 31: 247264.

Markman, G. D., P. T. Gianiodis, P.H. Phan and D. B. Balkin. 2005. "Innovation Speed: Transferring University Technology to Market.” Research Policy, 34: 1058-1075.

Max Planck Society. 2000. Handbook of Scientific Members. Munich.

Max Planck Society 2008. Annual Report 2007. Munich.

Mora-Valentin, E. M., A. Montoro-Sanchez and L. Guerras-Martin. 2004. “Determining factors in the success of R\&D cooperative agreements between firms and research organizations.” Research Policy, 33: 17-40. 
Mowery, D. C., R. R. Nelson, B. N. Sampat and A. A. Ziedonis. 2001. "The growth of patenting and licensing by U.S. universities: an assessment of the effects of the BayhDole act of 1980.” Research Policy, 30: 99-119.

Murray, F. and S. Stern. 2007. "Do formal intellectual property rights hinder the free flow of scientific knowledge? An empirical test of the anti-commons hypothesis.” Journal of Economic Behavior and Organization, 63: 648-687.

Nelson, R. R. (ed.) 1993. National Innovation Systems - A Comparative Analysis. New York: Oxford University Press.

Nelson, R. R. 2004. “The market economy, and the scientific commons.” Research Policy, 33: 455-471.

Nooteboom, B. 1999. "Innovation and inter-firm linkages: new implications for policy.” Research Policy, 28: 793-805.

Phan, P. H. and D. S. Siegel. 2006. “The Effectiveness of University Technology Transfer.” Foundations and Trends in Entrepreneurship, 2: 77-144.

Rosenbloom, P. R. and D. B. Rubin. 1983. "The central role of the propensity score in observational studies for causal effects.” Biometrika, 70: 41-55.

Shane, S. 2002. “Selling University Technology: Patterns from MIT.” Management Science, 48: 122-137.

Shane, S. and T. Stuart. 2002. "Organizational Endowments and the Performance of University Start-Ups.” Management Science, 48: 154-170.

Shapiro, C. 2000. "Navigating the Patent Thicket: Cross Licenses, Patent Pools, and Standard Setting.” Innovation Policy and the Economy, 1: 119-150.

Sianesi, B. 2001. "Implementing Propensity Score Matching Estimators with STATA.” Prepared for the UK Stata Users Group, VII Meeting, London, May 2001.

Stephan, P. 1996. “The Economics of Science.” Journal of Economic Literature, 34: 11991235.

Teece, D. J. 1986. "Profiting from technological innovation: Implications for integration, collaboration, licensing and public policy.” Research Policy, 15: 285-305.

Teece, D. J., G. Pisano and A. Shuen. 1997. "Dynamic Capabilities and Strategic Management.” Strategic Management Journal, 18: 509-533.

Verspagen, B. 2006. “University Research, Intellectual Property Rights and European Innovation Systems.” Journal of Economic Surveys, 20: 607-632. 
Von Ledebur, S., G. Buenstorf and M. Hummel. 2009. "University patenting in Germany before and after 2002: What role did the professors’ privilege play?” Jena Economic Research Papers \# 2009-068.

Wooldridge, J. W. 2002. Econometric Analysis of Cross Section and Panel Data. Cambridge MA: MIT Press.

Zellner, C. 2003. "The Economic Effects of Basic Research: Evidence for Embodied Knowledge Transfer via Scientists’ Migration.” Research Policy, 32: 1881-1895. 
Table 1a: Inventions disclosed by Max Planck researchers, 1980-2005

\begin{tabular}{c|c}
\hline Inventions & 2,251 \\
(patented) & 1,382 \\
\hline Licensed inventions & 721 \\
(patented) & 529 \\
First licensed to foreign firm & 184 \\
(patented) & 132 \\
First licensed to spinoffs & 195 \\
(patented) & 165 \\
\hline
\end{tabular}

Table 1b: License agreements with royalties by Max Planck researchers, 1980-2005

\begin{tabular}{c|c}
\hline Contracts & 729 \\
(patented) & 504 \\
\hline Commercialized & 365 \\
(patented) & 212 \\
\hline
\end{tabular}

Table 2a: Descriptive statistics I (Inventions)

\begin{tabular}{|c|c|c|c|c|c|c|}
\hline & \multicolumn{3}{|c|}{$\begin{array}{l}\text { All inventions } \\
\text { (2251) }\end{array}$} & \multicolumn{3}{|c|}{$\begin{array}{c}\text { Patented Inventions } \\
\text { (1382) }\end{array}$} \\
\hline & (mean) & $(\min )$ & $(\max )$ & (mean) & $(\min )$ & $(\max )$ \\
\hline Director-inventor & .133 & 0 & 1 & .179 & 0 & 1 \\
\hline Biomedical section & .601 & 0 & 1 & .591 & 0 & 1 \\
\hline Patent application & .634 & 0 & 1 & -- & -- & -- \\
\hline Time $(1980=0)$ & 14.648 & 0 & 25 & 14.371 & 0 & 24 \\
\hline Patent family size & -- & -- & -- & 5.431 & 1 & 120 \\
\hline Triadic Patent Family & -- & -- & -- & .250 & 0 & 1 \\
\hline Collaborative invention & -- & -- & -- & .211 & 0 & 1 \\
\hline
\end{tabular}


Table 2b: Descriptive statistics II (licensed inventions)

\begin{tabular}{c|cccccc}
\hline & \multicolumn{3}{|c}{$\begin{array}{c}\text { License contracts providing for } \\
\text { royalties (729) }\end{array}$} & \multicolumn{3}{c}{$\begin{array}{c}\text { Licensing contracts providing for } \\
\text { royalties (patented) (504) }\end{array}$} \\
\cline { 2 - 7 } & (mean) & (min) & (max) & (mean) & (min) & (max) \\
\hline Commercialization & .501 & 0 & 1 & .421 & 0 & 1 \\
Ln variable payments & 4.782 & 0 & 19.109 & 4.131 & 0 & 19.109 \\
Director-inventor & .383 & 0 & 1 & .433 & 0 & 1 \\
Biomedical section & .765 & 0 & 1 & .792 & 0 & 1 \\
Foreign Licensee & .331 & 0 & 1 & .317 & 0 & 1 \\
Spin-off Licensee & .272 & 0 & 1 & .321 & 0 & 1 \\
Time (1980=0) & 13.36 & 0 & 25 & 13.467 & 0 & 24 \\
Bundle & .287 & 0 & 1 & .361 & 0 & 1 \\
Repeat licensee & .757 & 0 & 1 & .819 & 0 & 1 \\
Patent application & .697 & 0 & 1 & -- & -- & -- \\
Patent family size & -- & -- & -- & 9.032 & 1 & 74 \\
Collaborative invention & -- & -- & -- & .145 & 0 & 1 \\
\hline
\end{tabular}

Table 3a: Correlations between covariates I (all inventions)

\begin{tabular}{c|cccc}
\hline 2251 obs. & Time & Biomed & Dir. Involvem. & Patent \\
\hline Time & 1.000 & & & \\
Biomed & .083 & 1.000 & & \\
Director Involvement & .028 & .170 & 1.000 & 1.000 \\
Patent & -.014 & -.008 & .162 & \\
\hline
\end{tabular}

Table 3b: Correlations between covariates II (patented inventions)

\begin{tabular}{c|cccccc}
\hline 1382 obs. & Time & Biomed & $\begin{array}{c}\text { Director } \\
\text { Involvem. }\end{array}$ & $\begin{array}{c}\text { Patent } \\
\text { Family }\end{array}$ & $\begin{array}{c}\text { Triadic Pat. } \\
\text { Family }\end{array}$ & $\begin{array}{c}\text { Industry } \\
\text { Cooperation }\end{array}$ \\
\hline Time & 1.000 & & & & & \\
Biomed & .087 & 1.000 & & & & \\
Director Involvement & .036 & .200 & 1.000 & & & \\
Patent Family & -.051 & .148 &. .221 & 1.000 & & \\
Triadic Patent Family & -.224 & -.037 & .137 & .446 & 1.000 & \\
Industry Cooperation & .052 & -.123 & -.028 & .111 & .194 & 1.000 \\
\hline
\end{tabular}


Table 4a: Correlations between covariates III (all licensed inventions)

\begin{tabular}{|c|c|c|c|c|c|c|c|c|}
\hline 729 obs. & Foreign & Spinoff & Time & Biomed & Dir. Inv.. & Patent & Bundle & M. Lic. \\
\hline Foreign & 1.000 & & & & & & & \\
\hline Spinoff & -.193 & 1.000 & & & & & & \\
\hline Time & -.016 & .255 & 1.000 & & & & & \\
\hline Biomed & .196 & .091 & .183 & 1.000 & & & & \\
\hline Dir. Involvement & .149 & .255 & .125 & .209 & 1.000 & & & \\
\hline Patent & -.044 & .175 & .022 & .086 & .157 & 1.000 & & \\
\hline Bundle & -.039 & .268 & -.006 & .029 & .194 & .253 & 1.000 & \\
\hline Repeat licencee & -.126 & .238 & .030 & .140 & .163 & .218 & .338 & 1.000 \\
\hline
\end{tabular}

Table 4b: Correlations between covariates IV (patented licensed inventions)

\begin{tabular}{|c|c|c|c|c|c|c|c|c|c|c|}
\hline 504 obs.. & For. & Spin. & Time & Biom. & $\begin{array}{l}\text { Dir. } \\
\text { Inv. }\end{array}$ & $\begin{array}{l}\text { Pat. } \\
\text { Fam. }\end{array}$ & Triade & $\begin{array}{c}\text { Ind. } \\
\text { Coop. }\end{array}$ & Bund. & $\begin{array}{l}\text { Mult. } \\
\text { Lic. }\end{array}$ \\
\hline Foreign & 1.000 & & & & & & & & & \\
\hline Spinoff & -.186 & 1.000 & & & & & & & & \\
\hline Time & -.117 & .230 & 1.000 & & & & & & & \\
\hline Biomed & .120 & .123 & .217 & 1.000 & & & & & & \\
\hline $\begin{array}{c}\text { Director } \\
\text { Involvement }\end{array}$ & .076 & .291 & .112 & .162 & 1.000 & & & & & \\
\hline Patent Family & .219 & -.079 & -.110 & .155 & .168 & 1.000 & & & & \\
\hline $\begin{array}{c}\text { Triadic Patent } \\
\text { Family }\end{array}$ & .103 & -.044 & -.203 & -.038 & .004 & .446 & 1.000 & & & \\
\hline Industry & -.123 & -.042 & .030 & -.080 & -.098 & .028 & .128 & 1.000 & & \\
\hline Cooperation & & & & & & & & & & \\
\hline Bundle & -.060 & .234 & -.069 & -.031 & .152 & .214 & .198 & .066 & 1.000 & \\
\hline Repeat licencee & -.212 & .224 & .024 & .115 & .118 & .128 & .115 & .061 & .331 & 1.000 \\
\hline
\end{tabular}




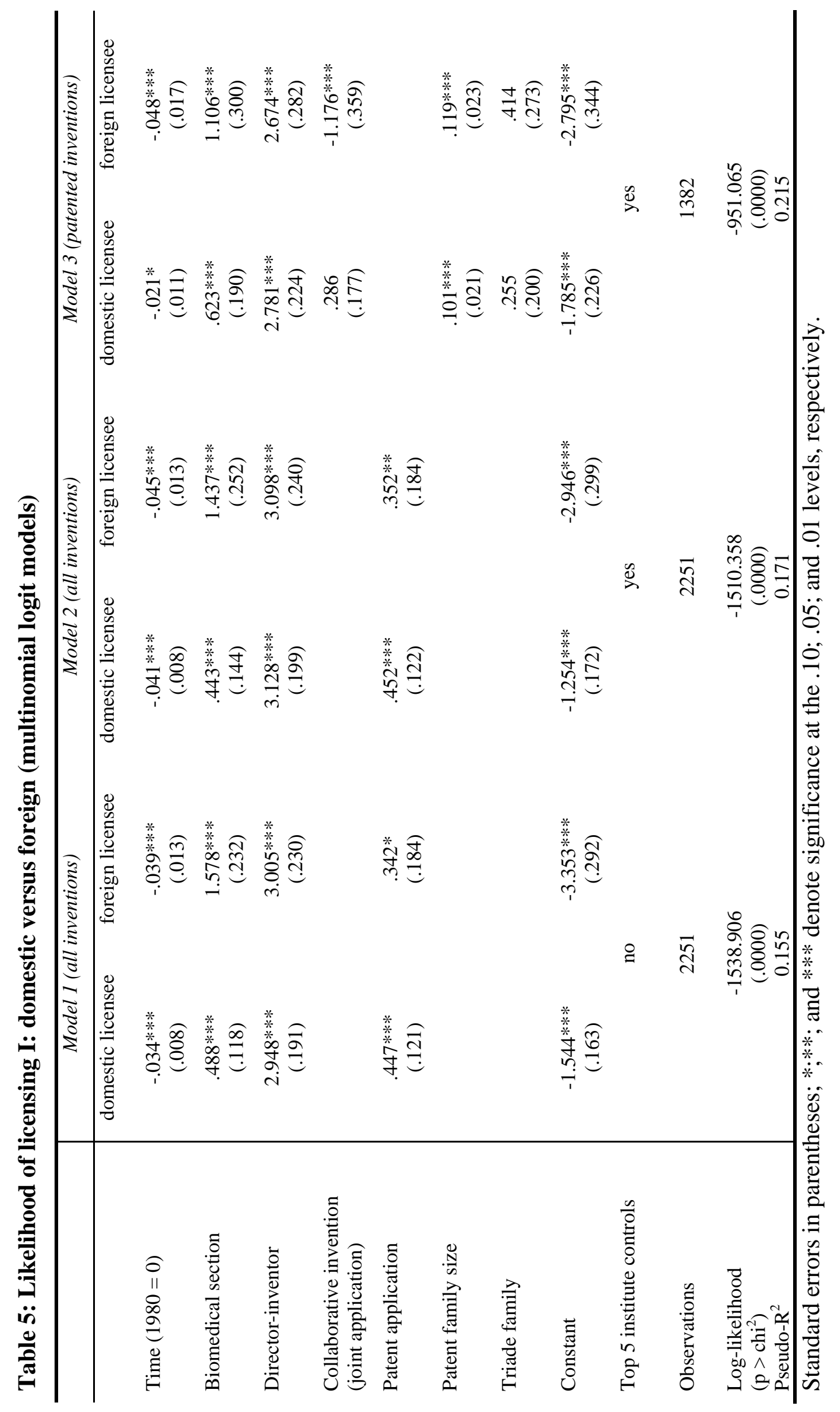




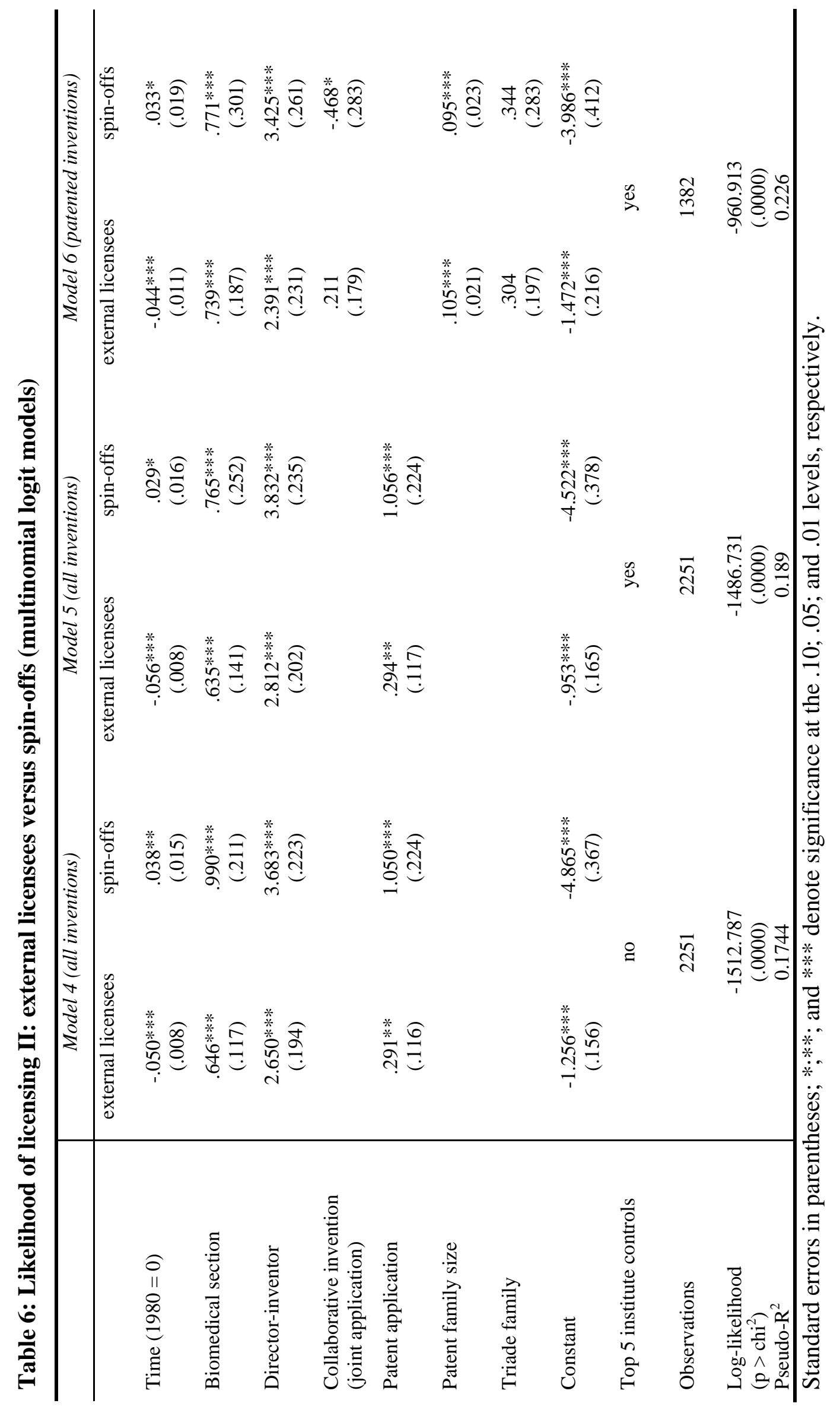




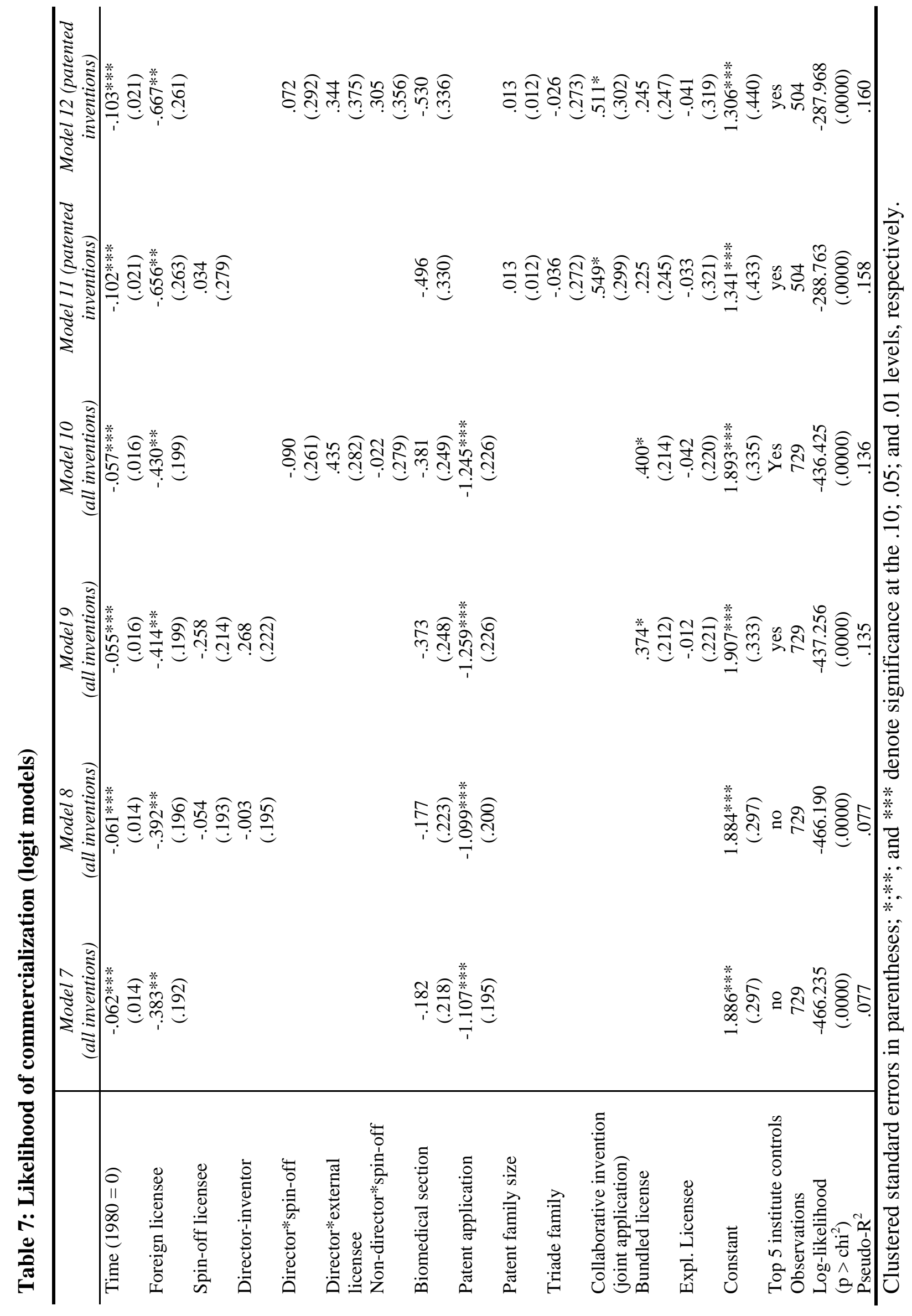




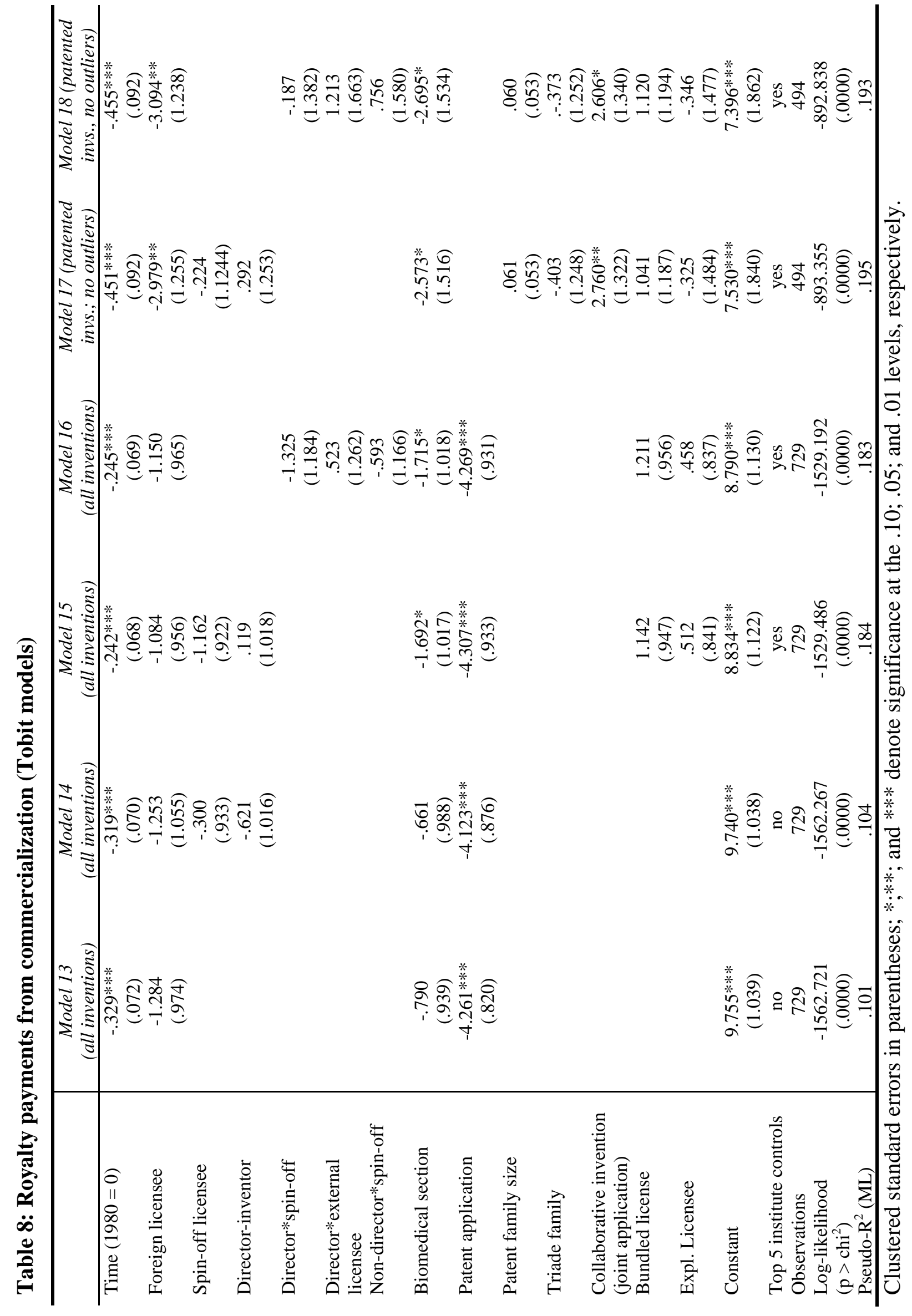


Table 9: Likelihood of commercialization (propensity score matching)

\begin{tabular}{c|cccccc}
\hline & \multicolumn{3}{|c}{ Model 19 (foreign vs. domestic) } & \multicolumn{3}{c}{ Model 20 (spin-off vs. external) } \\
\cline { 2 - 7 } & Unmatched & ATT & ATE & Unmatched & ATT & ATE \\
\hline Treated & .448 & .448 & & .383 & .383 & \\
Untreated & .526 & .506 & & .442 & .327 & \\
Difference & -.079 & -.058 & -.136 & -.059 & .055 & -.017 \\
S.E. (bootstrapped) & & .045 & .044 & & .056 & .056 \\
95\% Confid. interval & & -.134 & -.224 & & -.082 & -.113 \\
(bias corrected) & & .049 & -.055 & & .152 & .123 \\
\hline
\end{tabular}

Note: Kernel matching (Gaussian kernel; bandwidth $=.06$ ); standard errors obtained through bootstrapping $(\mathrm{n}=100)$ 